\title{
The limits to the use of international aid as a means of securing improvements in food production and nutrition
}

\section{By J. Seaman, Save the Children Fund (UK), Mary Datchelor House, i 7 Grove Lane, Camberwell, London $S_{5}$}

It is not a new observation, but it is an important one, that there are sharp limits to the use of international aid as a means of securing improvements in food production and nutrition in the developing countries. In the wake of famine in Africa and the vast public interest and expenditure on relief work, there is a natural tendency for aid donors to wish to invest more heavily in the permanent improvement of conditions in that continent. In this, there is a risk that the lessons of the past experience of the drought of $1968-73$ and the surge of international assistance which followed will not be learned and that much waste will result.

The present paper presents a personal view, based on the experience of initiating and reviewing aid projects in many developing countries, albeit on the modest scale of a non-governmental organization (NGO); and on the observation of the projects of several larger bilateral and multilateral agencies. That said, few if any of the ideas presented are original or have not been made often before.

It is important to begin with a reasonably clear definition of the objectives of development aid. For the purpose of this discussion I have assumed that, of the many possible, two are legitimate. The first is palliative or humanitarian. For example, the use of food aid as famine relief is often viewed as a short-term expedient intended to prevent death by starvation, although it may be noted that an equally important reason is to prevent a population becoming destitute through the sale of assets. The second is, in the context of this discussion, to secure a sustained improvement in the quantities of food produced and, by inference, improved food consumption and an improvement in the nutritional status (however this is defined) of the population concerned. The emphasis here is on the word sustained, for the obvious but often forgotten reason, that it is easy to secure with outside funding a short-lived effect for either objective. To quote a widely used slogan, it is better to teach a man to fish than to give a man a fish. The question addressed here is to what extent is this a practical choice?

International aid is, like any source of finance, an investment. The success of an investment, to use the jargon, depends on the return exceeding the opportunity cost forgone. International aid, whether on a small scale from NGOs or on a large scale from multilateral sources, e.g. the United Nations or bilateral (government-to-government) sources, has no magical quality which separates it from other sources of finance, except perhaps for the fact that it is sometimes interest-free, and that if the investment fails the investor is not likely to go bankrupt. 
Two sets of constraints affect the successful investment of international aid. The first are those set by the conditions in which the money is spent. The second are the constraints, chiefly political and intellectual, which the donors of aid set for themselves. The successful use of aid to produce sustained improvement depends on the degree with which one can reach an accommodation with the other.

\section{Constraints on investment in increased food production}

A view of the Third World farmer which is still current in some development literature and in much media presentation is of a passive 'ignorant' individual who farms inefficiently and to little effect. From time-to-time the rain will fail and he and his family will become dependent on international relief. Much investigation, and all common observation suggests the reverse is true; that is, that the Third World farmer or herdsman is highly skilled. By and large, he is capable, within the information available and the physical constraints of soils and weather, of producing an optimal return on the value of his, and his family's labour, land and capital. If he sometimes trades off long-term capital, in the form of the destruction of the environment, for short-term gain, then he is little different to his Western counterpart in, say, East Anglia. At least the Third World farmer has the defence that the short-term gain is often his own survival rather than the difference in price between a Ford and a Jaguar car.

In many of the poorer developing countries the main opportunity for obtaining a secure income does not lie in farming at all, but in off-farm work. The prices of agricultural commodities are too low. In large areas of the African Sahel, agriculture is marked by an ageing workforce and the cultivation of some crops is often reduced to the status of little more than gardening.

In a study with which I was involved in a village in The Gambia in 1979, the average age of male groundnut farmers was found to be over 50 years. Any young able-bodied man, particularly if literate, would find work in the cities or, if ingenious enough, in Western Europe, for the reason that the returns were not only more (and often much more) than could be obtained from groundnuts, but were also much more reliable and above all consistent. It could be shown that an illiterate night-watchman could earn more than a groundnut farmer, even if the rains were good and the monkeys did not dig up the crop. Swamp rice-cultivation has survived to a much greater extent, for the reason that it is done by women, for whom off-farm work is less easy to obtain.

Under these conditions, where the return on agriculture is so low that only those with no alternative do it, it is difficult to see what international aid can do quickly or permanently to improve the situation, at least more than marginally. Better seeds might improve the return a little. But serious investment, for example in the fencing of remote fields to reduce the damage from wild pigs, could not conceivably, at the prevailing prices, repay the investment.

Elsewhere, these difficulties are compounded by a lack of roads and the high costs of transport, and in significant geographic areas by the effects of war. Fertilizer and other farm inputs may not be available, and even where their use 
would be profitable they may be lacking because of shortage of foreign exchange or maladministration. The story may be apocryphal but it is said that a West African farmer, when asked to describe his problems replied that 'the rains do not come and the agricultural department does.'

In addition, it must be added that in many areas, the farmer is in more or less direct competition with the heavily subsidized farmers of Western Europe and North America. If the farmer does not grow enough food, but can find cash, imported food can be obtained at much lower prices and higher quality than it can be locally produced. In 1985 wheat could be landed in many African ports for around $\{100 /$ tonne; rice is currently little more expensive.

The point may be made by the success of some aid projects in the same latitude as Africa. Simple donkey- or ox-drawn ploughs have enjoyed some success, to the extent that in some areas farmers will travel long distances to buy them. Rice cultivation in low-lying wet areas has certainly been successfully extended by aid projects; chiefly in that case by volunteer programmes which survey the areas and provide instruction and appropriate seed. However, the impression is that the enthusiasm of farmers for these projects results not from the desire to maximize agricultural production but rather to make more productive use of the residual available labour, depleted by long-term and permanent migration. Other crops which partly serve the same economic purpose have spread widely and successfully elsewhere without the intervention of international aid, and probably with much greater impact on food consumption. Cassava, for example, was until recently confined almost exclusively to the wetter coast of West Africa. Within the past $3^{\circ}$ years it has spread inland to much dryer zones.

In each country of the developing world the constraints are different. In some they are much-less severe. In large parts of India, where labour is cheap, the food economy is closed to the outside world, and there is a steady and unmet demand from the urban middle class. Successful investment in agricultural production is relatively straightforward, in that the limits are set primarily by the availability of land and by the skills of the individual concerned. Where both requirements are satisfied, investment in, say, fish farming, dairy cattle or poultry production on a small commercial scale may be entirely successful. The product can be sold at a profit consistently and without difficulty. The job of the donor may only be to provide capital.

The point is, however, that the success of international assistance in increasing food production depends on a combination of political, administrative, social and above all economic constraints in the locality concerned. On a small scale, and with ingenuity, suitable economic 'niches' for investment can be found almost anywhere, but aid cannot ride roughshod over the much larger effects of national and global policies and economics.

As is well known, the corollary to the increased production of food is not necessarily the improved consumption of food by the producer or better nutrition for a population. Where food is produced on commercial plantations, or where land is owned by a small proportion of the population and when, as is often the case, 
there is a considerable surplus of unskilled labour, the farm labourer may not benefit at all.

A small proportion of developing countries have policies which seek deliberately to ensure the redistribution of food within the population. Sri Lanka, for example, has long had such a policy, although its impact is now rapidly being eroded by the cost of the guerrilla war in the north of the island. Where countries do not have such policies, it is usually not in the power of aid donors to introduce them. On occasion it may be possible to design programmes in such a way as to attempt to redistribute the product. For example, some deep-tube well projects in Bangladesh, which will produce an additional winter crop, are organized to give control of water to the landless, who then sell it to farmers. However, with surplus labour and no enforceable labour legislation such arrangements must in the long-term be fragile.

\section{Technical constraints on food production}

It is probably a reasonable proposition that, given enough capital, skill and application, almost any crop system in the Third World can be induced to produce a larger and sustained output. In recent years a new class of problem has emerged where this is not the case. This results from the destruction of the environment to an extent that there is no known technical solution, even if economic and other constraints were removed. One such case is provided by the Red Sea Hills Province, adjacent to Port Sudan. Here a population of several hundred thousand Beija and Hadendowa, comprising virtually two complete pastoral nations, are destitute and there appears to be no technical possibility of restoring the original economy.

\section{Direct approaches to improving nutritional status}

In most parts of the developing world, it is technically straightforward to substantially improve the nutritional status of a population by the direct distribution of food or of specific nutrients such as vitamin $A$. The best-evaluated examples are from captive populations, such as refugees, where all food supplies and nutritional and other services are externally supplied and controlled, where political constraints may apply to only a small extent and where ample resources are usually available. Under such conditions it is often possible to improve nutritional status, at least in terms of the absence of severe malnutrition and deficiency diseases, to the levels which characterize Western populations.

Projects of this sort have been widely run in the developing countries by foreign agencies and have been much encouraged by the easy availability of food aid from the food surpluses in the Western countries. Projects which aim to directly improve nutritional status take broadly two forms. First, food distribution projects, where usually a few hundred kcal of food/head per $\mathrm{d}$ may be distributed in schools, to children under 5 years of age or to specified nutritional categories. The second is effectively confined to the current effort to distribute vitamin $A$ in areas where this is deficient in the diet. 
Leaving aside the question of the effectiveness of many food distribution projects, and the social and economic undesirability of solving nutritional problems with handouts, both face the same difficulty. That is, that neither is likely to achieve either widespread coverage of a population or sustained impact unless the country concerned has already an infrastructure capable of reaching a useful proportion of the population. The cost of setting up independent distribution systems is in absolute terms too high for this to be possible in larger countries; and even if done, there is no way in which these can be sustained in the long run. Some headway is being made with the low-cost extension of services, chiefly through systems of 'primary health care', but it is as yet too soon to judge their long-term success.

\section{Donor constraints}

The donor organizations, whether government, multilateral or NGO, are themselves subject to a series of constraints which limit their freedom of action. Some of these are directly political. For example, the reluctance of some Western donors to release food as famine relief for Ethiopia would fall into this category, although there are many more subtle examples which tend to escape the notice of the public. A possibly more important effect which is incidental to the nature of Western government, is the violent swings in policy and the resulting discontinuities in project funding which can result from a change in administration in a donor country. Another is bureaucratic. For example, the co-ordination and management of the bilateral-multilateral relation sometimes seems to demand a number of co-ordinating missions and committees approximating to the factorial of the number of agencies involved. This inevitably reduces the efficiency with which aid can be spent.

These constraints are perhaps inevitable and beyond change. There is, however, one other constraint which does reduce the effectiveness with which aid is spent. That is, the intellectual environment in which aid is spent.

Although in the present paper I have not attempted to be prescriptive, the corollory to what $I$ have said is that in many cases, international aid should not, indeed cannot, be seeking short-term benefits in terms of agricultural production and nutrition. Rather, it should often be concerned with setting the preconditions for possible agricultural and nutritional change. For example, it can, and often has, been argued that in the long run, primary education will have a greater impact on the agricultural development of Africa than will direct project aid; or that international aid might be used to advantage in underwriting the administrative costs of Third World governments. Direct involvement in agricultural development and nutrition programmes, if these are to be effective, must inevitably be protracted, and the approach must be flexible and to an extent opportunistic.

I suspect that this view would enjoy support from many aid administrators, who are faced with the practical problems of programme design and management in a complex and rapidly changing world. There are, however, many other views as to the optimal approach to aid expenditure. Some of these are politically partisan, 
others simply naive (for example, the constant quest for 'new' technologies which will solve specific economic and nutritional problems in the developing countries). One, however, is particularly intrusive, and that is the increasing pressure on agencies to provide quantified evidence of performance, which works in many instances directly against the effective use of aid. Some aid projects are now so constrained by the process that programme design itself is compromised in order to produce outputs which are accessible to quantification. At its silliest, it leads to situations such as one recently in Ethiopia, where the beneficiaries of one source of food had to be selected in advance so that they could then be monitored for growth. This is difficult to achieve when those in need are coming from remote rural areas and wish to return with food for their families.

Elsewhere, the requirement for quantified evidence of impact can conflict with common sense. For example a school lunch programme, which uses imported food and is managed by the Save the Children Fund was once reviewed by the donor, who wanted evidence of nutritional impact. The reply was that this could not be done because every schoolchild in the country was fed and there was therefore no possible control: and that the objective of the programme was simply to provide lunch for schoolchildren, a desirable end in itself. 